\title{
Diferansiyel Evrim Algoritması Uç Öğrenme Makinesi (DGA-UÖM) Kullanarak Derin Özelliklere Dayalı EKG İşareti Sınıflandırma Tekniği
}

\author{
Aykut DİKER ${ }^{1 *}$ Engin AVCI ${ }^{2}$ \\ ${ }^{1}$ Bandırma Onyedi Eylül University, Department of Software Engineering, Bandirma, Balıkesir \\ ${ }^{2}$ Firat University, Faculty of Technology, Department of Software Engineering, Elazig \\ (ORCID: 0000-0002-1207-8548) (ORCID: 0000-0001-6278-3221)
}

\begin{abstract}
The movements of electrocardiogram (ECG) signals are very important in the diagnosis of heart disorders. Machine learning methods are widely used to classify ECG signals. The aim of this work is to contribute to the classification of ECG signals using the Differential Evolution Algorithm Extreme Learning Machine (DGA-ELM). In this paper, a public heart records in Physionet was utilized to classify ECG signals. The pre-processing was applied to eliminate the ECG signals from noise. Then, the ECG signals were converted to spectrograms for the feature extraction stage. A method was used originated on Convolutional Neural Network (CNN) to obtain the attributes of ECG signals. The DGA-ELM algorithm was used to select the best activation function. In this context, the best cost value $79.37 \%$ with a sigmoid activation function and 750 iteration in the classification made with DGA-ELM was achieved.
\end{abstract}

Anahtar kelimeler: Electrocardiogram, Differential Evolution Algorithm, Classification, Spectrogram.

\section{ECG Signal Classification Technique Based on Deep Features Using Differential Evolution Algorithm Extreme Learning Machine (DEA-ELM)}

\section{$\ddot{O} z$}

Elektrokardiyogram (EKG) işaretlerinin hareketleri kalp hastalıklarının teşhisinde çok önemlidir. Makine öğrenme yöntemleri, EKG işaretlerini sınıflandırmak için yaygın olarak kullanılmaktadır. Bu çalışmanın amacı, Diferansiyel Evrim Algoritması Uç Öğrenme Makinesinin (DGA-UÖM) kullanarak EKG işaretlerinin sınıflandırılmasına katkıda bulunmaktır. Bu çalışmada, EKG iaşretlerini sınıflandırmak için Physionet'teki açık erişimli kalp kayıtları kullanılmıştır. EKG işaretlerini gürültüden arındımak için ön işlem süreci uygulanmıştır. Daha sonra, özellik çıkarımı aşaması için EKG işaretleri spektogramlara dönüştürülmüştür. EKG işaretlerinin özelliklerini elde etmek için Konvolüsyonel Sinir Ağına (KSA) dayanan bir yöntem kullanılmıştır. DGA-UÖM algoritması en iyi aktivasyon fonksiyonun seçmek için kullanılmıştır. Bu bağlamda, DGA-UÖM ile yapılan sınıflandırmada sigmoid aktivasyon fonksiyonu ve 750 iterasyon ile \% 79.37 en iyi maliyet değerine ulaşılmıştır.

Keywords: Elektrokardiyogram, Diferansiyel Gelişim Algoritması, Sınıflandırma, Spektogram.

\section{Introduction}

The Electrocardiogram (ECG) is an alteration of the human heart. ECG's have comprised of different critical areas. These sections are P, QRS complex and T, which is seen as in Figure 1 [1-4]. Throughout atrial depolarization, the $\mathrm{P}$ wave comprises. QRS wave that can be separated partitions happens $[1,2]$. Detection and classification of the ECG has become one of the most notable powerful and unique instruments in the ECG applications [5, 6]. Furthermore, the timely diagnosis of heart disease is a very important for humans suffers from heart trouble. Analysis of ECG is of a very critical factor in the determination of heart diseases [7]. Particularly, ECG classification has been made effective algorithms by using computer-aid systems [8]. Researchers have developed many works for the identification and

"Sorumlu yazar: aykutdiker@gmail.com

Geliş Tarihi: 20.11.2019, Kabul Tarihi: 08.04.2020 
separate as normal and anormal of the heart record for many years. For examples of classification techniques are applied by Wavelet transform [9], Radial basis function technique [10], Support Vector Machine (SVM) [11], Extreme Learning Machine (ELM) [12], Deep learning method [13]. Deep learning is a new method that is have been done many studies in the literature. For example, Image classification [14], Biomedicine applications (etc. ECG signal classification) [15, 16] and Agriculture [17]. Deep learning structures are multiple levels and include many coefficients. Automatic encoders constrained Boltzman Machines and Convolutional Neural Networks (CNN's) are used structures which is common [18]. CNN's are one of the most studied structures and comprise of two-part these are feature extraction and classify $[18,19]$.CNN, which is a specialized architecture of deep learning, is particularly successful in image processing [20-22].

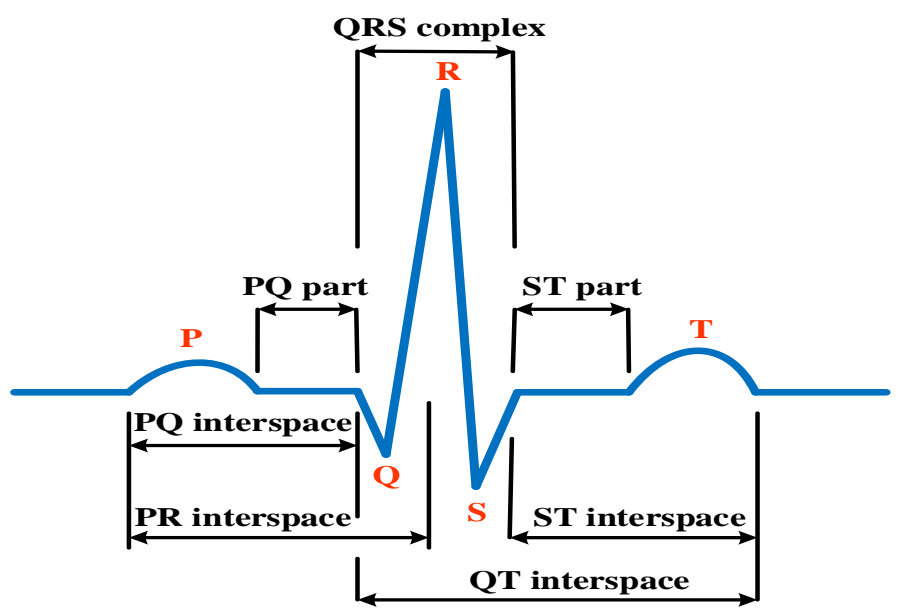

Figure 1. A typical ECG signal and important sections

Though, it has some difficulties such as the availability of local minima's, indefinite learning percentage, the election of the numeral of hidden neurons and overfitting [23, 24]. In order to solve the disadvantage of ELM, there are various nature-inspired population-based techniques with global search abilities such as Differential Evolutional (DE) [25, 26], Particle Swarm Optimization (PSO) [27], Genetic Algorithm (GA) [28], Ant Colony Optimization (ACO) [29], Artifical Bee Colony algorithm (ABC) [30]. The ECG diagnostic is employed generally features obtained from the $\mathrm{P}$ wave, QRS complex and $\mathrm{T}$ wave which are crucial sections of heart records. Meanwhile correct defining of the heart signals is a significant and critical process for the experts which is to make a correct detection decision. By using machine learning systems is detected of the heart signal has a major effect on the diagnostic of heart disease. In this study, the impact of the Differential Evolutional Extreme Learning Machine based (DEA-ELM) technique is analyzed of heart records. The novelty of our technique is the usage of by the most appropriate values, which is an efficient optimization method DEA for ECG classification to overcome the disadvantage (e.g determine of the best transfer function and the number of hidden neurons) of ELM. Besides, since accurate feature extraction is required for accurate ECG classification, the procedure that employs of deep features by using CNN which is based on deep learning techniques of ECG signals for feature extraction was utilized in this work. The main aim of this contribution is to determine the best activation function which is the above mentioned disadvantage of ELM to classify ECG signals by DEA.

The paper is organized as: the ECG records and method which is used in ECG separated as normal and abnormal are explained in Part 2. Classification results with DEA-ELM classifiers are given in Part 3. The concluding are present in respectively Part 4.

\section{Material and Method}

The blocks schema of the employed technique for ECG signal classification is remarked in Figure 2. This method can be divided into four sections as in Figure 2. Firstly, ECG signals are presented from the PTBDB database for the preprocessing. The preprocessing process is completed in two sections, as 
baseline-wandering and eliminating $60 \mathrm{~Hz}$ noise. After the preprocessing steps, ECG signals which are acquired from Physionet were converted to image using spectrogram. The next step of the block diagram is feature extraction that deep features are obtained from CNN. The next step of the proposed model is optimization and classification, in which the activation function of ELM are optimized. The last stage of the procedure is to classify the ECG signals.

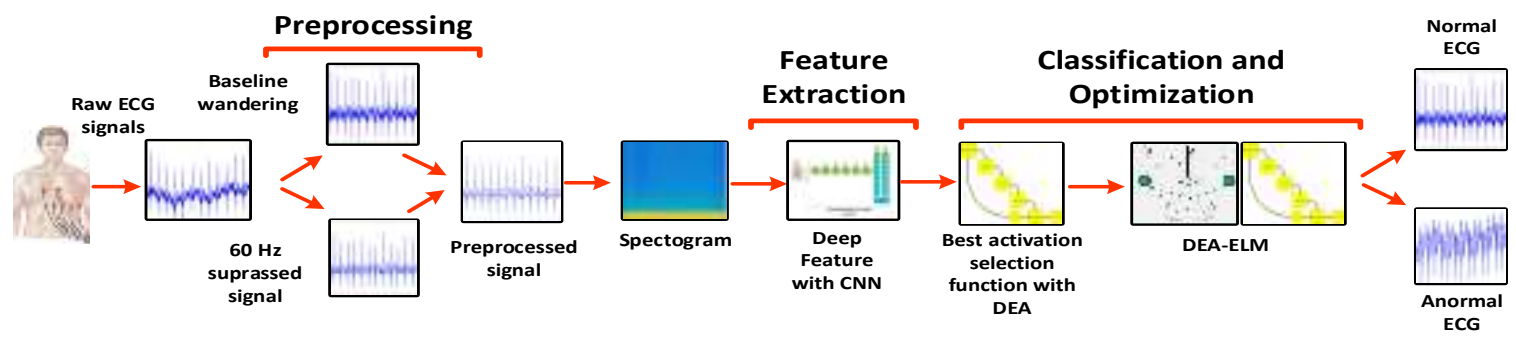

Figure 2. The scheme of the recommended structure of ECG signal classification

\subsection{Dataset description}

In this paper, so as to evaluate the adequacy of ELM classifiers, PTBDB which is publicly on the Physionet were utilized [31]. PTB ECG diagnostic dataset has totally 549 records. The samples were gathered from 294 patients. Each of the samples contains 15 synchronously registered signals. Heart signals in the dataset are contained normal and different disorder classes as shown in Figure 3 [32, 33].

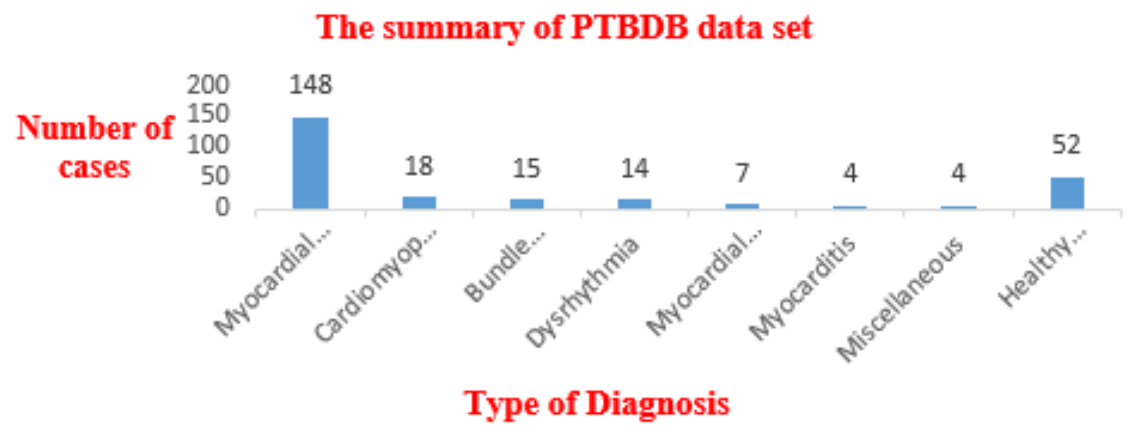

Figure 3. Distribution of diagnoses of PTB dataset

We achieved experimental study just on healthy and abnormal record. Therefore, 80 of abnormal and 80 healthy records were obtained from the PTB ECG database, separately. Besides, in this study, all measurements were obtained from lead II on the PTB database as seen in Figure 4.

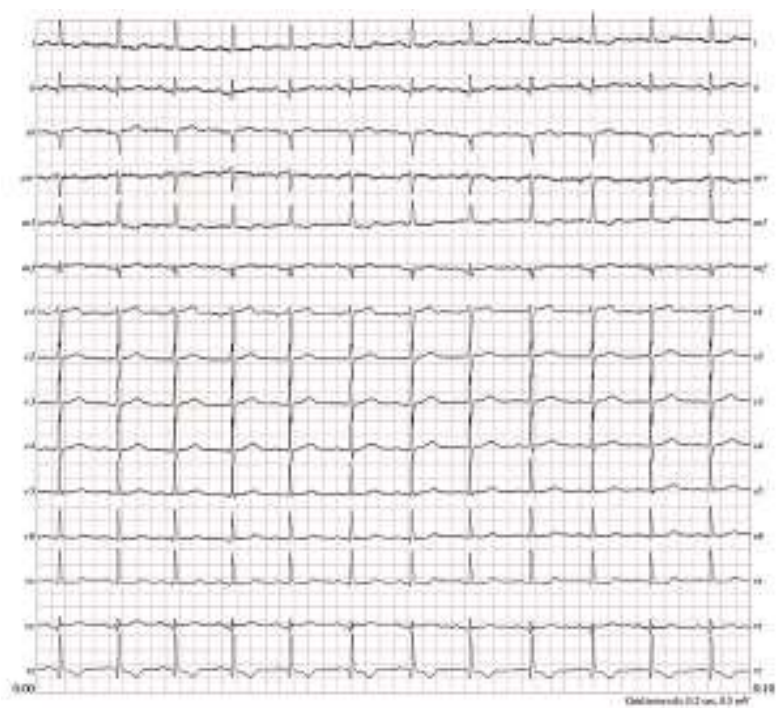

Figure 4. ECG recording in the PTB dataset [34] 


\subsection{Preprocessing}

Noise and interference can be undesirable which is it causes oscillations in signal processing applications. ECG involves an excessive number of unrestful noises, so this step has an important task for ECG classification application [35],[36]. Furthermore, it is applied as a usual analysis stage in most biomedical practice to obtain stable and clear signals. ECG signals include various types of disturbance, like baseline wandering and structure interactions. The symlet filter and the denoising operate were employed to correct the baseline wandering In addition, line interactions and system interactions were decreased at this step. Then, these disturbances on heart recordings were eliminated using the SavitzkyGolay filter given in Figure 5.

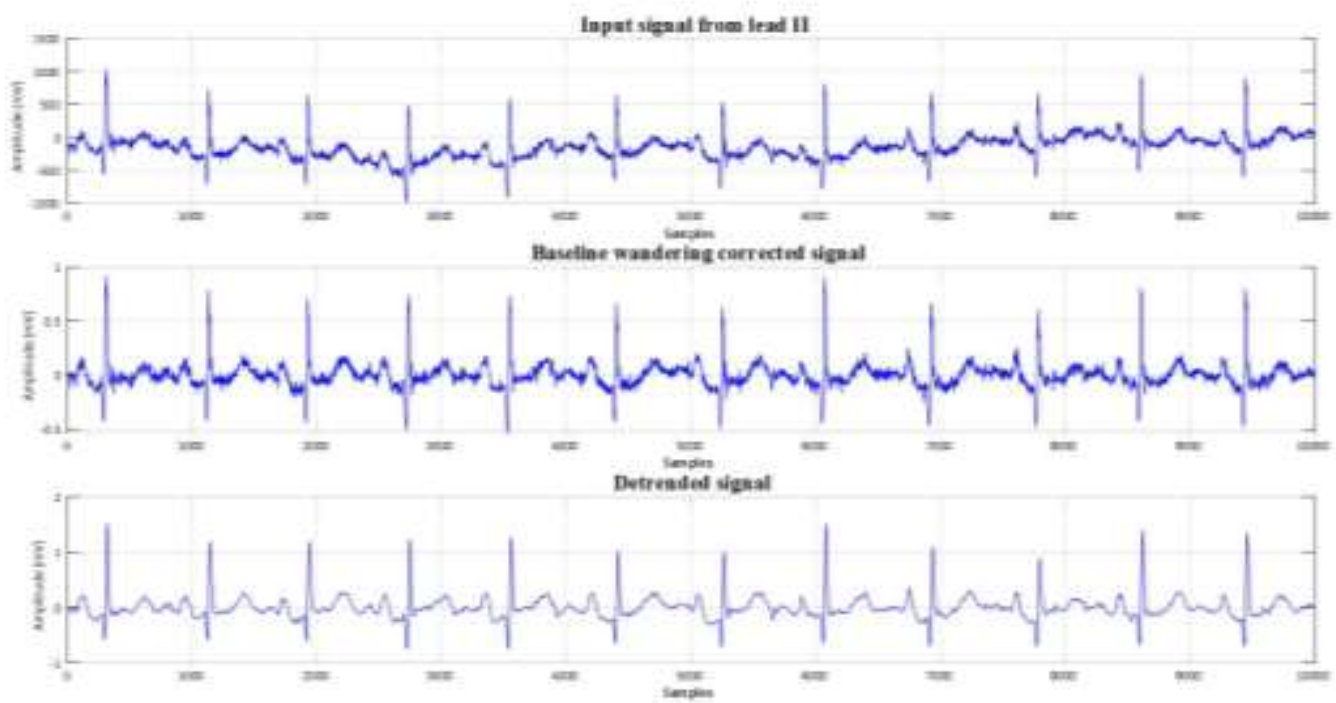

(a)

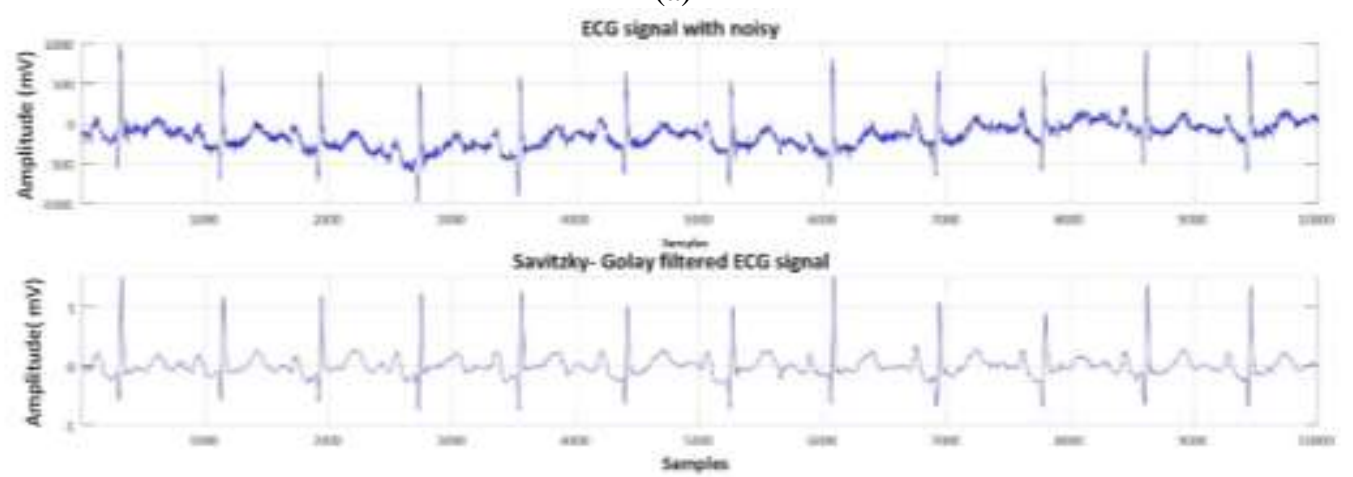

(b)

Figure 5. (a) Preprocessed ECG signal (b) Savitzky-Golay applied ECG signal

\subsection{Feature Extraction}

The extraction of specific properties from biomedical signals (ECG, EEG, etc.) is an important step for the classification process. Following the preprocessing step, it is required to achieve the characteristic properties for utilization in the last phase. In this study, were obtained deep feature by using CNN. Therefore, AlexNet structure has used which is obtained from Convolutional Neural Network architectures.

\subsubsection{Convolutional Neural Network Structure}

CNN's are a derivative of multiple structures generated which is based on biology [18]. CNN has become a popular method on account of processing capabilities in various applications [37, 38]. CNN's 
are consist of a lot of stages as shown in Figure 6. In each stage has three stages which are including the attribute pooling stage, the filter bank stage, and the non-linear stage. There are many kernels in the filter bank stage for diverse attribute subtraction.

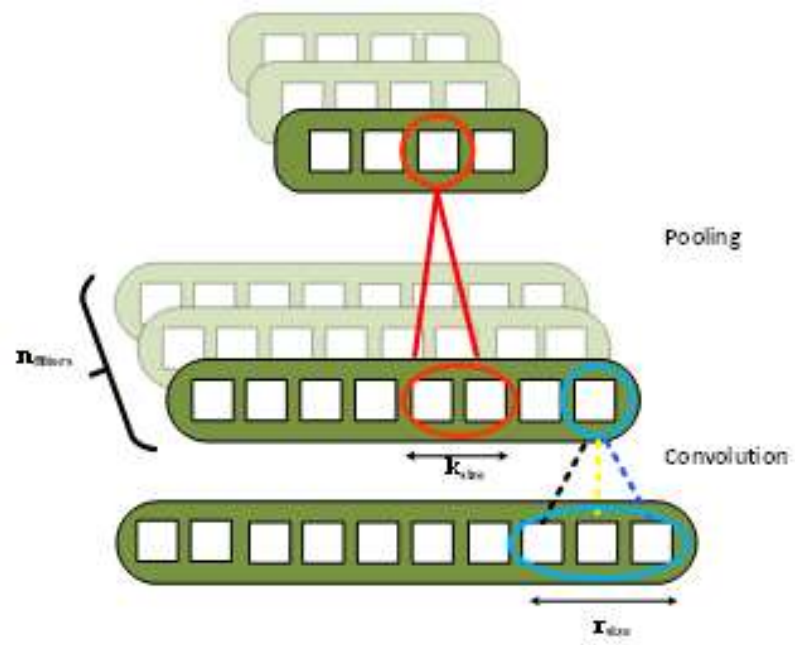

Figure 6. Convolutional network structure

In the pooling stage, every attribute project is processed apart from. Every project ensures the mean or maximal rate of the adjacent rate [18].

\subsubsection{Layers used in CNN structure}

In this study, AlexNet is used which is a $\mathrm{CNN}$ architecture to take out attributes. Convolution stages have implicated Input-Convolution-ReLu-Pooling-Fully connected stages. Rectified linear unit (ReLU) used in AlexNet architecture is the activation function which is a very fast learning speed. ReLU has a higher performance than sigmoid and tanh which are other activation functions. The ReLU activation function fulfills a threshold process to each input element where values less than zero are set to zero thus the ReLU is dedicated by Equations 1,

$$
f(x)=\max (0, x)= \begin{cases}x_{i}, & \text { if } x_{i} \geq 0 \\ 0, & \text { if } x_{i}<0\end{cases}
$$

ReLU verifies the values of inputs less than zero and thus forces them to zero and eliminates the vanishing gradient problem observed in previous activation function types [39]. The CNN structure used to the extraction of attributes of the heart records attained from the spectrograms is seen in Figure 7.

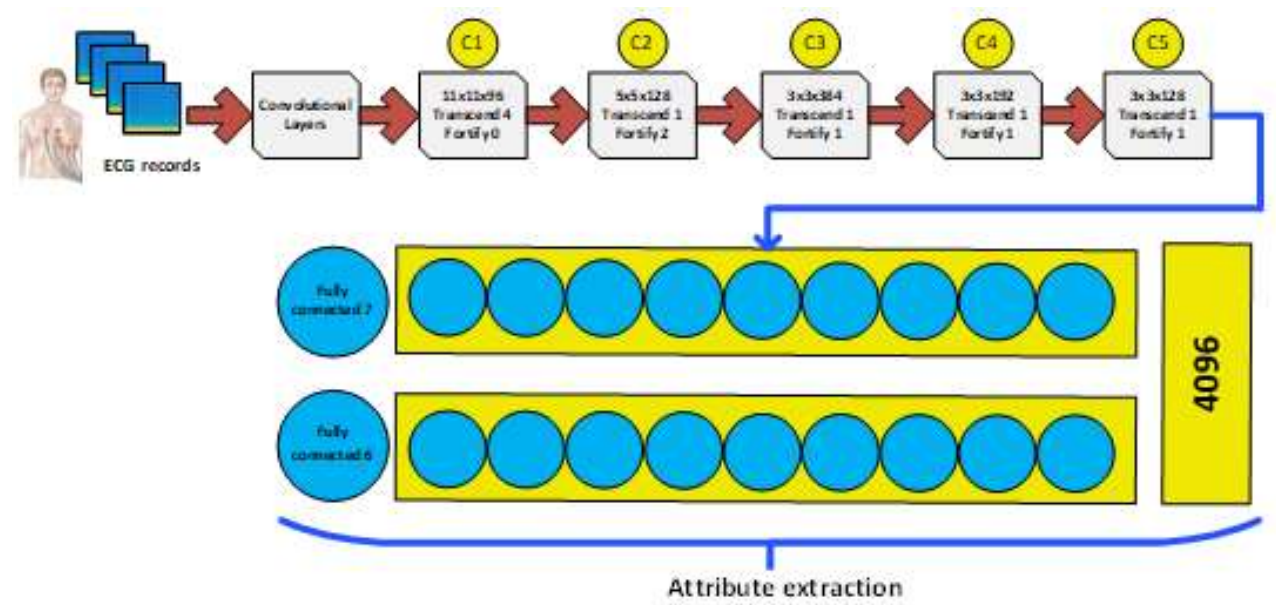

Figure 7. CNN architecture used in this study. 


\subsection{Extreme Learning Machine}

A machine learning technique called ELM was put forward by ref [23] which is the last step weights may only set throughout training. Furthermore, these weights casually are assigned with other weights and thresholds [23],[24],[40]. The ELM scheme is as seen in Figure 8. ELM is a comprehensive type of SLFN and the hidden layer is not essential to set. SLFN structure is indicated in Figure 8.

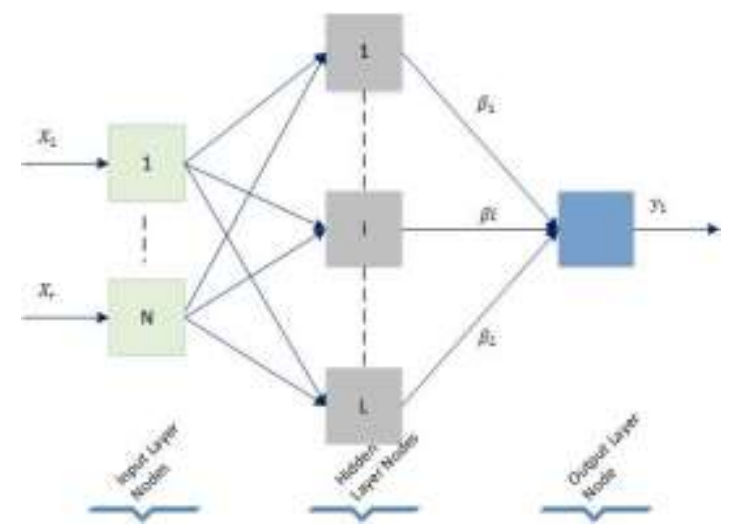

Figure 8. SLFN structure

For $\mathrm{N}$ arbitrarily diverse instance $\left(x_{i}, t_{i}\right)$, the ordinary with $\mathrm{H}$ covert nodes and the transfer function $h(x)$ is explicated by $x_{i}=\left[x_{i 1}, x_{i 2}, \ldots . x_{i D}\right]^{T} \in R^{D}$ and $t_{i}=\left[t_{i 1}, x_{i 2}, \ldots . x_{i K}\right]^{T} \in R^{K}$. SLFNs are comprised as is given in Equation 2:

$$
\sum_{i=1}^{L} \beta_{i} h_{i}\left(x_{j}\right)=\sum_{i=1}^{L} \beta_{i} h_{i}\left(w_{i} \cdot x_{j}+b_{i}\right)=o_{j}, \quad j \in 1, N
$$

On the contrary, the norms in the machine learning structures indicate that all covert nodes that need to be set in the structure are covert nodes/ structures which are composed of coincidentally in the ELM learning procedure. Hidden node indexes are the basis for objective functions or training datasets. The hidden node indexes in ELM are not only separate for themselves but also separate, with standard SLFN with hidden nodes that have a detailed technique and partitioning capability $[23,24,40]$. ELM architecture is as in Figure 9.

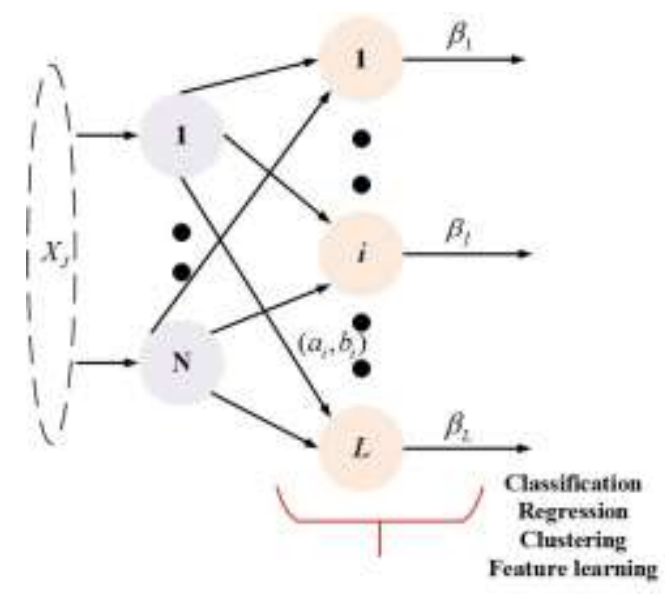

Figure 9. ELM structure

Unlike traditional learning methods, the ELM method can incidentally generate hidden node coefficients. In Equation $1, w_{i}=\left[w_{i 1}, w_{i 2}, \ldots . w_{i D}\right]^{T}$, is the weight vector connected to the hidden node and the input nodes, $\beta_{i}=\left[\beta_{i 1}, \beta_{i 2}, \ldots . w_{i K}\right]^{K}$ is the weight vector and $b_{i}$ is the ith node. $\mathrm{h}(\mathrm{x})$ transfer object and hidden nodes $\mathrm{L}$ are given in Equations 3, 4, 5 . 


$$
\begin{aligned}
& H=\left[\begin{array}{ccc}
h_{1}\left(w_{1} x_{1}+b_{1}\right) & \cdots & h_{L}\left(L x_{1}+b_{L}\right) \\
\vdots & \ddots & \vdots \\
h_{1}\left(w_{1} x_{N}+b_{1}\right) & \cdots & h_{L}\left(w_{L} x_{N}+b_{L}\right)
\end{array}\right]_{N x M} \\
& \beta=\left[\begin{array}{c}
\beta_{1}^{T} \\
\vdots \\
\beta_{L}^{T}
\end{array}\right]_{M x 1} \text { and } \quad T=\left[\begin{array}{c}
t_{1}^{T} \\
\vdots \\
t_{L}^{T}
\end{array}\right]_{N \times 1}
\end{aligned}
$$

$\mathrm{H}$ is called the hidden part output sample, the ith column of $\mathrm{H}$ is the ith hidden neurons output vector. Additionally, ELM is formulated as in Equation 6.

$$
\beta=H^{\dagger} T
$$

$H^{\dagger}$, characterize Moore-Penrose, the universalize inverse of $\mathrm{H}$ matrix to earn a least-square solve $[23,40-43]$.

\subsection{Differential Evolution Algorithm}

Many problems encountered in science, in social sciences, and in application fields of theirs can be modeled as linear or nonlinear optimization problems. Most of the problems in the application have a non-linear structure. There are many techniques, which is have been developed to solve non-linear problems. The difficulty ratings of the troubles can be also increase based on the number of variables and data types. The solution of such troubles by deterministic techniques has problems both in modeling and in the solving process based on the problem architecture. Heuristic techniques have been improved to accomplish the above problems. Particularly, heuristics the population-based can produce results quickly thanks to multi-point search procedures. One of the improved algorithms for solving the problems of continuous parameters is the Differential Evolutional Algorithm (DEA) which is developed by Price and Storm in 1995 [44]. DEA is a population-based heuristic optimization method which is based on Genetic Algorithms (GA) in terms of operations and operators, and it is can provide effective results which especially in cases continuous data is the problems [44-46]. Meanwhile, DEA is performed research at many points. During the iterations, better results for the solution of the problem with the help of the operators are searched. Besides, aim of DEA is to improve the solution performance of the problems in which coding with real values is used, with some changes in genetic operators. Crossing, mutation, and selection operators in GA are also used in the DEA. Unlike GA, each operator is not applied to the whole population respectively. Chromosomes are processed one by one and it is obtained a new individual using a random selection of three other chromosomes. Throughout this operations, mutation and crossover processors are used. The suitability of the young chromosome obtained and with the existing chromosome are comparing, and it is transmitted to the following population as a young individual with better fitness. Thus, the selection operator is also used. The quality of the solutions produced is measured by the value they produce for the objective function (fitness value) [44]. The main advantages and important parameters of the DEA algorithm as can be inferred in Table

\begin{tabular}{|c|c|}
\hline Advantages & $\begin{array}{ll}\text { - } & \text { Simple Structure } \\
\text { - } & \text { Ease of use } \\
\text { - } & \text { Speed and robustness }[47,48] .\end{array}$ \\
\hline Parameters & $\begin{array}{ll}\text { - } & \text { NP (Number of Population-size) } \\
\text { - } & \text { CR (Crossover Rate) } \\
\text { - } & \text { F (Scaling Factor) [49]. }\end{array}$ \\
\hline
\end{tabular}
2 ;

Table 2. Advantages and important parameters of DEA algorithms.

An optimization involving the $\mathrm{D}$ parameter can be symbolized by a $\mathrm{D}$ vector. A population of NP population vectors is produced initially randomized in DEA. This population is accomplished 
developed by performing mutation, crossover and selection processors [49]. The major stages of the DEA can be given as seen in Figure 10. The number of variables of the problem determines the number of genes for each chromosome. The population size (number of chromosomes) in DEA should always be greater than 3 , because three chromosomes are required except for the existing chromosome for the production of new chromosomes.

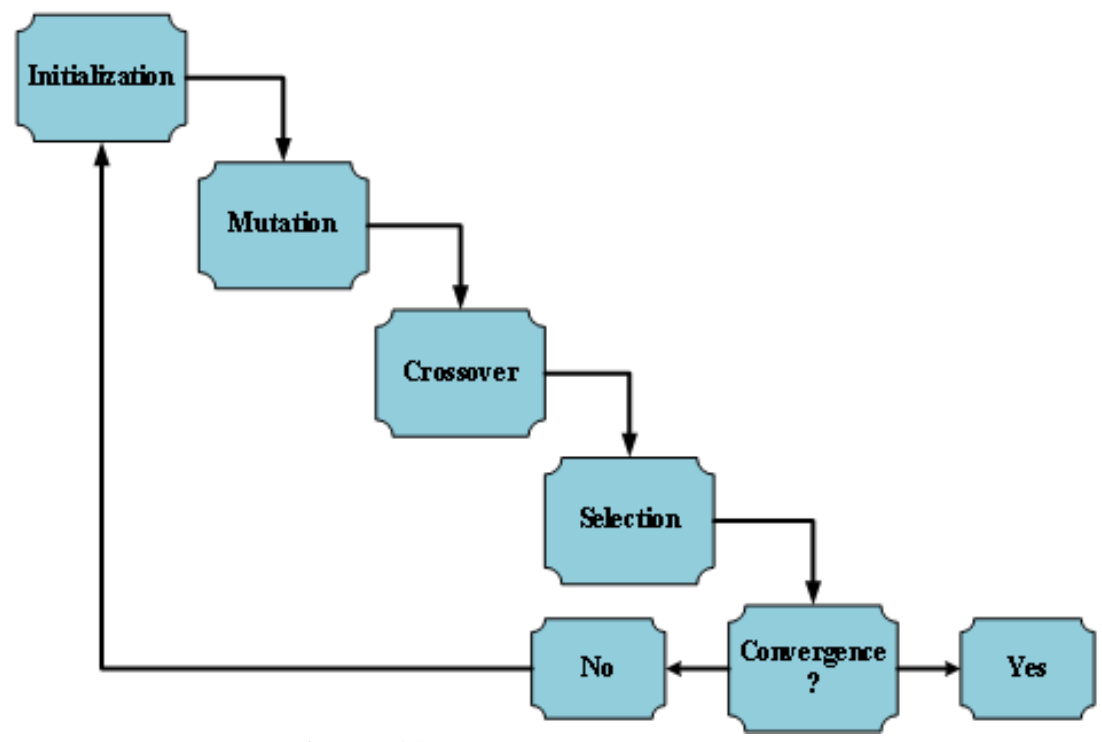

Figure 10. Differential algorithm steps

The mutation is to make changes in randomly determined amounts on some part genes of the present chromosome. Thanks to these various, the solution spot showed by its chromosome moves in the solution domain. In order for the mutation to reach its goal, the changes must be determined in the right direction and the right quantity of movement should be determined. In the DEA, three chromosomes are selected apart from the chromosomes to be exposed to mutation. The first two of chromosomes which is of selected are taken the difference. Then, this difference chromosome is multiplied by the scaling factor parameter. This parameter usually takes values between $0-2$. With obtained weighted difference chromosome is collected with the selected third chromosome. Thus, the result of the mutation chromosome will be used in the crossover [44]. Figure 11 shows that DEA pseudo code used in this study.

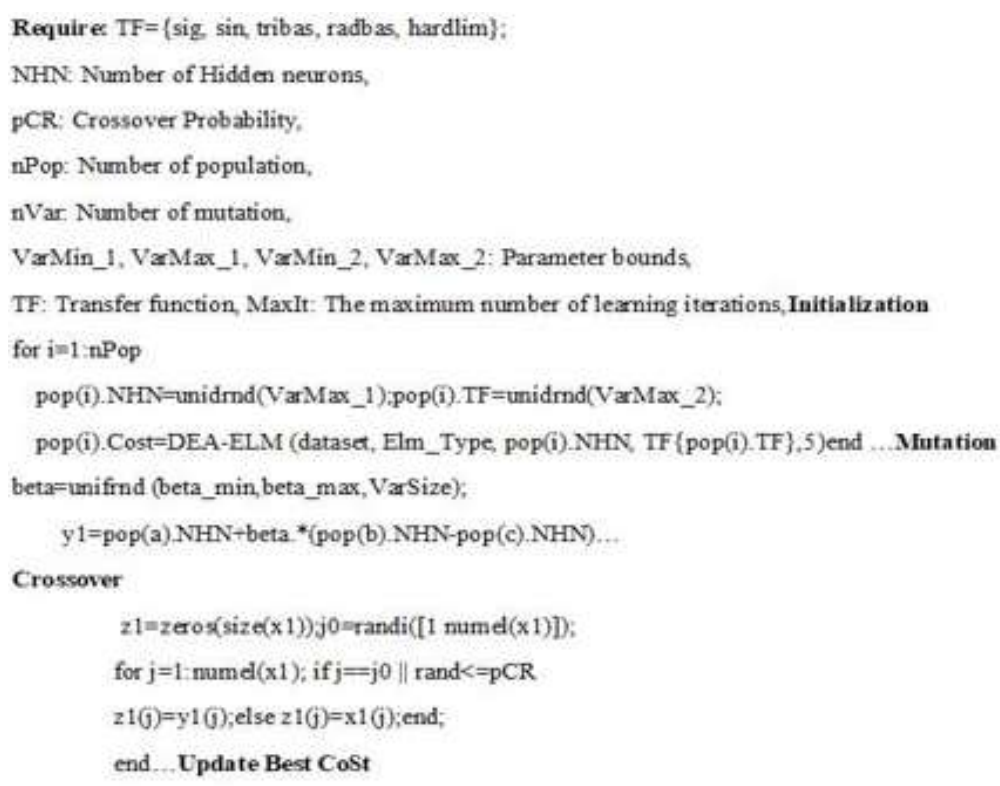

Figure 11. Pseudo code of DEA-ELM used in this study 


\section{Results}

This chapter indicates the DEA-ELM classifier operation for classifying the heart records Thus, the ECG signals which are comprised of 80 unhealthy and 80 normal records from publicly in Physionet were selected. Overall of the ECG records were showed with properties as described in Table 1. The system is performed on Intel Xeon $3.30 \mathrm{GHz}$ CPU and 8GB RAM hardware in the computer using MATLAB ${ }^{\circledR} 2018 \mathrm{a}$. Firstly, the preprocessing step was performed to remove the $60 \mathrm{~Hz}$ interference and the baseline wander of the ECG signals obtained from the PTB dataset. Afterward, the spectrograms were obtained to represent in the frequency domain the ECG signals to carry them to the stage of extraction with CNN is seen as Figure 12.

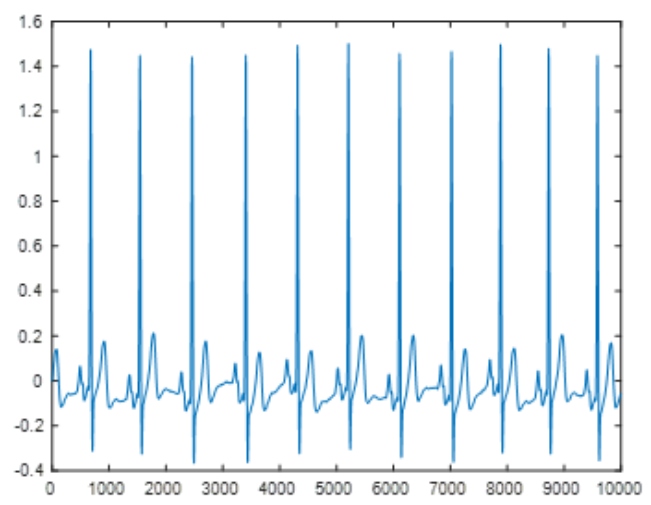

(c)

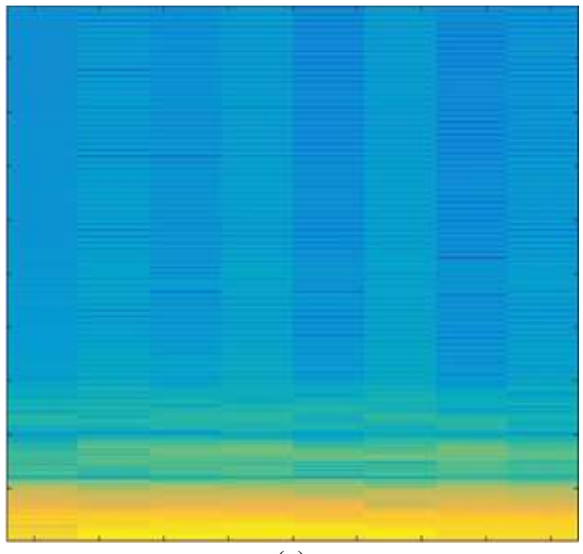

(a)

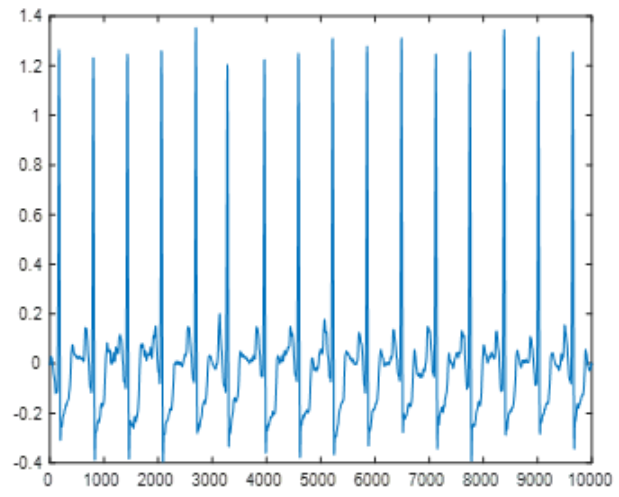

(d)

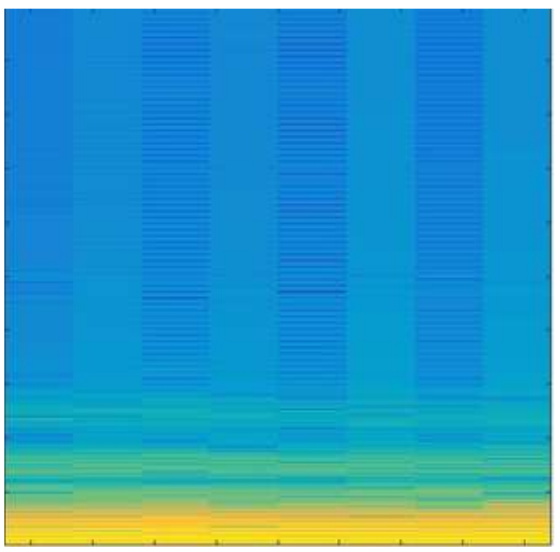

(b)

Figure 12. (a) Spectrogram of normal ECG record with number s02921re (b) Spectrogram of anormal ECG record with numbers0021brem (c) Normal ECG record with number s0292lre (d) Anormal ECG record with numbers0021brem

The entire data was split into two sequences as training and test in 10-fold cross-validation procedure. In this scope, $90 \%$ of data was used for training while the rest of data was used for testing in each round, as mentioned before. After the attribute extraction stage, the spectrogram images of the ECG signal were given to the DEA-ELM classifier. The best cost values obtained with DEA-ELM are given for various iterations as seen in Figure 13.

Performance values for 5 different activation functions (sigmoid, sinus, triangularbasis, radialbasis, hardlimit) were obtained with the DEA-ELM classifier as can be seen in Table 3. Moreover, the parameters used in the DEA algorithm are given in Table 3.

In the point out in Section 2.3, there are features extracted using CNN from ECG signals. DEA was employed which is a robust meta-heuristic optimization algorithm for ECG classification. This process was carried out as shown in Figure 13. Best costs as performance results were obtained by 100, $150,200,250,500,750$ and 1000 with the number of iterations DEA-ELM as shown in Figure 13. The major objective of this article is to classify the ECG signals by using DEA-ELM based on deep features with best activation function. We checked also whether the best cost value changed with more iterations. 
Consequently, the best cost value achieved was remained stable at 1000 iteration numbers as mentioned in Figure 13.

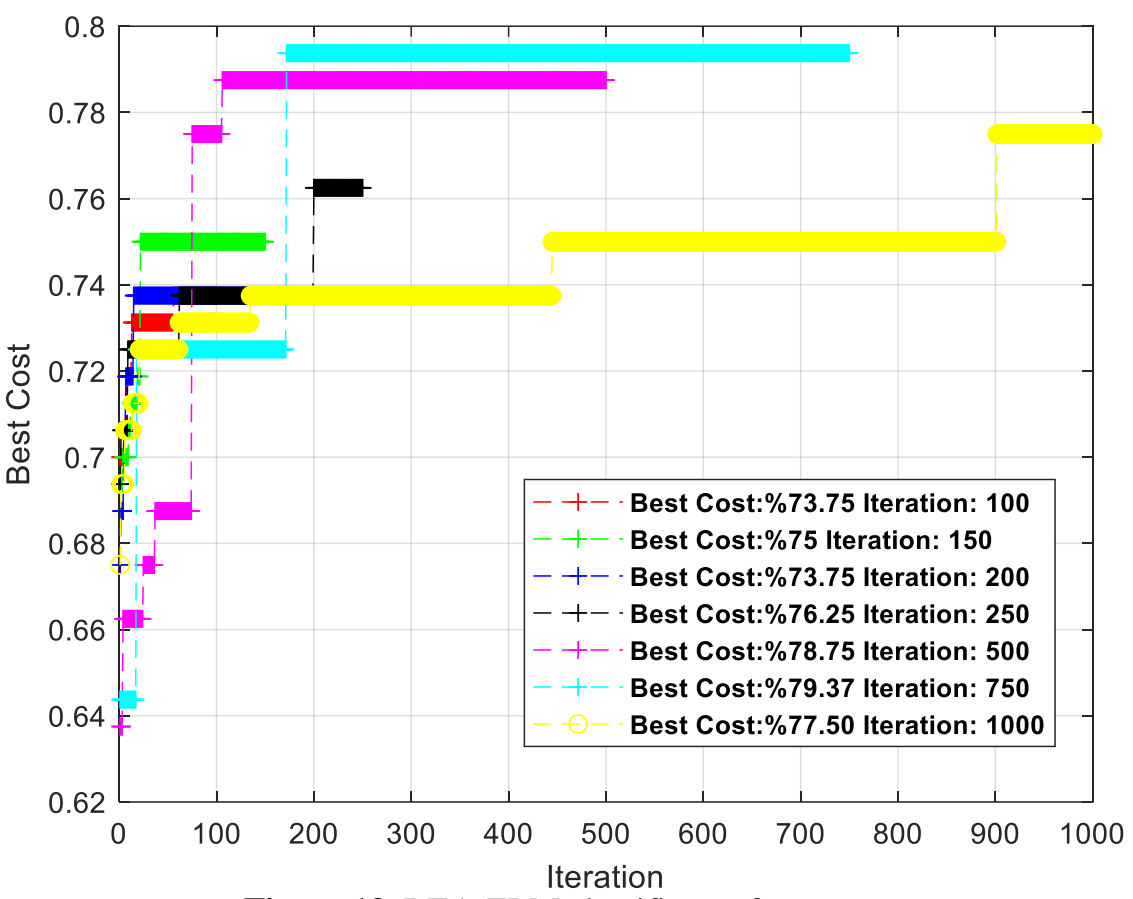

Figure 13. DEA-ELM classifier performance

Table 3. DGA parameters used in the study

\begin{tabular}{|l|l|}
\hline Parameter & Value \\
\hline Population & 160 \\
\hline Mutation & 0.1 \\
\hline Crossover & 0.8 \\
\hline Parameter bounds & Min $=1$, Mak $=5$ \\
\hline Number of iteration & $100,150,200,250,500,750,1000$ \\
\hline Stopping criteria & Until it reaches the best cost value. \\
\hline
\end{tabular}

\section{Conclusion}

The aim of this paper was to classify records from database in order to clarify the diagnosis of heart disorders. For realizing this purpose, the best activation function of the extreme learning machine was selected using the differential evolution algorithm method. In this study, the performance results of the DEA-ELM method based on deep features for the classification of ECG signals were examined. The model was tested employing the open access PTB Diagnostic ECG database. In addition, the features of the ECG signal by using CNN were extracted. Consequently, the best classification results values using DEA-ELM the best cost value $\% 79.37$ with sigmoid activation function and 750 iteration were achieved.

\section{Authors' Contributions}

All the authors actively participated in the literature analysis, the interpretation of results and the preparation of the manuscript. All authors read and approved the final manuscript.

\section{Statement of Conflicts of Interest}

There is no conflict of interest between the authors.

\section{Statement of Research and Publication Ethics}

The authors declare that this study complies with Research and Publication Ethics. 


\section{References}

[1] Teodoro F.G.S., Peres S.M., Lima C.A. 2017. Feature selection for biometric recognition based on electrocardiogram signals. In 2017 International Joint Conference on Neural Networks (IJCNN), IEEE, 2911-2920.

[2] Diker A., Avci E., Gedikpinar M. 2017. Determination of R-peaks in ECG signal using Hilbert Transform and Pan-Tompkins Algorithms. In 2017 25th Signal Processing and Communications Applications Conference (SIU), IEEE, 1-4.

[3] Ojha D.K., Subashini M. 2014. Analysis of electrocardiograph (ecg) signal for the detection of abnormalities using matlab. World Academy of Science, Engineering and Technology, International Journal of Medical, Health, Pharmaceutical and Biomedical Engineering, 8 (2): 114 117.

[4] Sadhukhan D., Mitra M. 2012. Detection of ECG characteristic features using slope thresholding and relative magnitude comparison. In 2012 Third International Conference on Emerging Applications of Information Technology, IEEE, 122-126.

[5] Kulkarni S.P. 2015. DWT and ANN Based Heart Arrhythmia Disease Diagnosis from MIT-BIH ECG Signal Data. International Journal on Recent and Innovation Trends in Computing and Communication, 3 (1): 276-279.

[6] Escalona-Morán M.A., Soriano M.C., Fischer I., Mirasso C.R. 2014. Electrocardiogram classification using reservoir computing with logistic regression. IEEE Journal of Biomedical and health Informatics, 19 (3): 892-898.

[7] Mannurmath J.C., Raveendra M. 2014. MATLAB based ECG signal classification. International Journal of Science, Engineering and Technology Research (IJSETR), 3 (7): 1946-1950.

[8] Pasolli E., Melgani F. 2015. Genetic algorithm-based method for mitigating label noise issue in ECG signal classification. Biomedical Signal Processing and Control, 19: 130-136.

[9] Rai H.M., Trivedi A., Shukla S. 2013. ECG signal processing for abnormalities detection using multi-resolution wavelet transform and Artificial Neural Network classifier. Measurement, 46 (9): 3238-3246.

[10] Korürek M., Doğan B. 2010. ECG beat classification using particle swarm optimization and radial basis function neural network. Expert systems with Applications, 37 (12): 7563-7569.

[11] Khorrami H., Moavenian M. 2010. A comparative study of DWT, CWT and DCT transformations in ECG arrhythmias classification. Expert systems with Applications, 37 (8): 5751-5757.

[12] Karpagachelvi S., Arthanari M., Sivakumar M. 2011. Classification of Electrocardiogram signals with extreme learning machine and relevance vector machine. International Journal of Computer Science Issues (IJCSI), 8 (1): 338.

[13] Wu J.F., Bao Y.L., Chan S.C., Wu H.C., Zhang L., Wei X.G. 2016. Myocardial infarction detection and classification-A new multi-scale deep feature learning approach. In 2016 IEEE International Conference on Digital Signal Processing (DSP), IEEE, 309-313.

[14] Liu D., Jiang Y., Pei M., Liu S. 2018. Emotional image color transfer via deep learning. Pattern Recognition Letters, 110: 16-22.

[15] Cao C., Liu F., Tan H., Song D., Shu W., Li W., Xie Z. 2018. Deep learning and its applications in biomedicine. Genomics, proteomics \& bioinformatics, 16 (1): 17-32.

[16] Labati R.D., Muñoz E., Piuri V., Sassi R., Scotti F. 2019. Deep-ECG: Convolutional neural networks for ECG biometric recognition. Pattern Recognition Letters, 126: 78-85.

[17] Kamilaris A., Prenafeta-Boldú F.X. 2018. Deep learning in agriculture: A survey. Computers and electronics in agriculture, 147: 70-90.

[18] Cengil E., Çınar A. 2016. A New Approach for Image Classification: Convolutional Neural Network. European Journal of Technique, 6 (2): 96-103.

[19] Doğan R.Ö., Kayikçioğlu T. 2018. R-peaks detection with convolutional neural network in electrocardiogram signal. In 2018 26th Signal Processing and Communications Applications Conference (SIU), IEEE, 1-4.

[20] Traore B.B., Kamsu-Foguem B., Tangara F. 2018. Deep convolution neural network for image recognition. Ecological informatics, 48: 257-268.

[21] Harangi B. 2018. Skin lesion classification with ensembles of deep convolutional neural networks. Journal of biomedical informatics, 86: 25-32. 
[22] Dos Santos Ferreira M.V., de Carvalho Filho A.O., de Sousa A.D., Silva A.C., Gattass M. 2018. Convolutional neural network and texture descriptor-based automatic detection and diagnosis of glaucoma. Expert Systems with Applications, 110: 250-263.

[23] Huang G.B., Zhu Q.Y., Siew C.K. 2006. Extreme learning machine: theory and applications. Neurocomputing, 70 (1-3): 489-501.

[24] Huang G.B., Zhou H., Ding X., Zhang R. 2011. Extreme learning machine for regression and multiclass classification. IEEE Transactions on Systems, Man, and Cybernetics, Part B (Cybernetics), 42 (2): 513-529.

[25] Villarreal-Cervantes M.G., Rodríguez-Molina A., García-Mendoza C.V., Penaloza-Mejia O., Sepúlveda-Cervantes G. 2017. Multi-objective on-line optimization approach for the DC motor controller tuning using differential evolution. IEEE Access, 5: 20393-20407.

[26] Hu J., Wang C., Liu C., Ye Z. 2017. Improved K-means algorithm based on hybrid fruit fly optimization and differential evolution. In 2017 12th International Conference on Computer Science and Education (ICCSE), IEEE, 464-467.

[27] Melgani F., Bazi Y. 2008. Classification of electrocardiogram signals with support vector machines and particle swarm optimization. IEEE transactions on information technology in biomedicine, 12 (5): 667-677.

[28] Avci E. 2013. A new method for expert target recognition system: Genetic wavelet extreme learning machine (GAWELM). Expert Systems with Applications, 40 (10): 3984-3993.

[29] Chen X., Zhang P., Du G., Li F. 2018. Ant colony optimization based memetic algorithm to solve bi-objective multiple traveling salesmen problem for multi-robot systems. IEEE Access, 6: 21745-21757.

[30] Farahani H.F., Rashidi F. 2017. Optimal allocation of plug-in electric vehicle capacity to produce active, reactive and distorted powers using differential evolution based artificial bee colony algorithm. IET Science, Measurement \& Technology, 11 (8): 1058-1070.

[31] Goldberger A.L., Amaral L.A., Glass L., Hausdorff J.M., Ivanov P.C., Mark R.G., Stanley H.E. 2000. PhysioBank, PhysioToolkit, and PhysioNet: components of a new research resource for complex physiologic signals. Circulation, 101 (23): e215-e220.

[32] Berkaya S.K., Uysal A.K., Gunal E.S., Ergin S., Gunal S., Gulmezoglu M.B. 2018. A survey on ECG analysis. Biomedical Signal Processing and Control, 43: 216-235.

[33] Vozda M., Peterek T., Cerny M. 2014. Novel Method for Deriving Vectorcardiographic Leads Based on Artificial Neural Networks.

[34] PhysioBank ATM. 2018. https://physionet.org/cgi-bin/atm/ATM. (Accessed: 10.07.2018).

[35] Cömert Z., Kocamaz A.F. 2015. Determination of QT interval on synthetic electrocardiogram. In 2015 23nd Signal Processing and Communications Applications Conference (SIU), IEEE, 25692572.

[36] Diker A., Cömert Z., Avcı E. 2017. A Diagnostic Model for Identification of Myocardial Infarction from Electrocardiography Signals. Bitlis Eren University Journal of Science and Technology, 7 (2): 132-139.

[37] Cömert Z., Kocamaz A.F. 2018. Fetal hypoxia detection based on deep convolutional neural network with transfer learning approach. In Computer Science On-line Conference, Springer, Cham., 239-248.

[38] Note O. 2017. Deep Convolutional Neural Network for ECG-Based Human Identification, 7-10.

[39] Nwankpa C., Ijomah W., Gachagan A., Marshall S. 2018. Activation functions: Comparison of trends in practice and research for deep learning. arXiv preprint arXiv:1811.03378.

[40] Huang G.B., Zhu Q.Y., Siew C.K. 2004. Extreme learning machine: a new learning scheme of feedforward neural networks. Neural networks, 2: 985-990.

[41] Huang G.B., Chen L., Siew C.K. 2006. Universal approximation using incremental constructive feedforward networks with random hidden nodes. IEEE Trans. Neural Networks, 17 (4): 879892.

[42] Huang G.B., Zhu Q.Y., Siew C.K. 2004. Extreme learning machine: a new learning scheme of feedforward neural networks. Neural networks, 2: 985-990.

[43] Kim J., Shin H.S., Shin K., Lee M. 2009. Robust algorithm for arrhythmia classification in ECG using extreme learning machine. Biomedical engineering online, 8 (1): 31. 
[44] Keskintürk T. 2006. Differential evolution algorithm. Istanbul Commerce University Journal of Science, 9: 85-99.

[45] Yang W.A., Zhou Q., Tsui K.L. 2016. Differential evolution-based feature selection and parameter optimisation for extreme learning machine in tool wear estimation. International Journal of Production Research, 54 (15): 4703-4721.

[46] Engelbrecht A.P. 2007. Computational intelligence: an introduction. John Wiley \& Sons.

[47] Qin A.K., Huang V.L., Suganthan P.N. 2008. Differential evolution algorithm with strategy adaptation for global numerical optimization. IEEE transactions on Evolutionary Computation, 13 (2): 398-417.

[48] Karc1 A. 2017. Differential Evolution Algorithm and Its Variants. Anatolian Science-Bilgisayar Bilimleri Dergisi, 2 (1): 10-14.

[49] Karaboğa N., Koyuncu C. 2005. A. Diferansiyel Gelişim Algoritmasi Kullanilarak Adaptif Lineer Toplayıc1 Tasarımı. 